УДК 621.396 .96

\title{
ОШИБКИ ПЕЛЕНГАЦИИ ЦЕЛИ ПРИ ВОЗДЕЙСТВИИ ВНЕШНИХ ШУМОВЫХ ИЗЛУЧЕНИЙ НА РЛС С ДВУМЕРНЫМИ АНТЕННЫМИ РЕШЕТКАМИ
}

\author{
РЯБУХА В. П., СЕМЕНЯКА А. В., РАЧКОВ Д. С., КАТЮШИН Е. А. \\ Харьковский национальный университет радиоэлектроники, \\ Украина, Харьков, 61166, пр-т Науки, 14
}

\begin{abstract}
Аннотация. Описана математическая модель, позволяющая исследовать флуктуационные и систематические ошибки измерения угловых координат цели в РЛС с плоскими ФАР при воздействии внешних источников шумовых излучений. Приведены результаты моделирования
\end{abstract}

Ключевые слова: пеленгация; среднеквадратическая ошибка; смещение; математическая модель

\section{ВВЕДЕНИЕ}

Актуальность исследования ошибок пеленгации (измерение угловых координат) нешумящей цели в условиях внешних пространственно-коррелированных шумовых излучений обусловлена тем, что эти исследования имеют свои особенности. В этом случае угловой параметр приобретает энергетический характер [1], т.е. величина отношения сигнал/(помеха + шум) (ОСПШ) $\mu(\alpha)$ на выходе устройства оптимальной пространственной обработки зависит от значения угловой координаты $\alpha$ (азимута $\beta$ или угла места $\varepsilon$ ). При этом компенсация шумовых излучений изменяет результирующую (оптимальную) диаграмму направленности (ДН) адаптивной антенной решетки (АР) [1-3].

В литературе результаты таких исследований приведены для РЛС с линейными АР $[1,4-7]$. Показано, что для случаев, когда один источник шумовых излучений (ИШИ) и цель расположены в одном элементе углового рэлеевского разрешения, т.е. в пределах главного лепестка ДН АР (рис. 1a), или не-

DOI: $10.20535 / \mathrm{S} 0021347016060029$

( Р Рябуха В. П., Семеняка А. В., Рачков Д. С., Катюшин Е. А., 2016 сколько ИШИ действуют по боковым лепесткам, но распределены неравномерно в пространстве, т.е. несимметрично относительно нормали к антенной решетке (рис. 1б), тогда наряду с флуктуационными возникают и систематические ошибки пеленгации нешумящей цели.

В данной работе исследованы флуктуационные и систематические ошибки пеленгации нешумящих объектов цели в РЛС с плоскими двумерными $N \times M$-элементными фазированными антенными решетками (ФАР) при воздействии ИШИ в направлении главного и боковых лепестков суммарной ДН ФАР.

В разделе 1 описана математическая модель, позволяющая исследовать флуктуационные и систематические ошибки измерения угловых координат цели в РЛС с плоскими ФАР при воздействии внешних ИШИ. Отличительная особенность модели - использование специфики ФАР, связанной с прямоугольной (квадратной) формой апертуры и эквидистантным расположением идентичных излучателей вдоль главных осей. Эта специфика позволяет 